\title{
Coral bleaching and recovery from 2016 to 2017 at East and West Flower Garden Banks, Gulf of Mexico
}

\author{
Michelle A. Johnston ${ }^{1} \cdot$ Emma L. Hickerson ${ }^{1} \cdot$ Marissa F. Nuttall ${ }^{2} \cdot$ \\ Raven D. Blakeway $^{2} \cdot$ Travis K. Sterne $^{2} \cdot$ Ryan J. Eckert $^{2,3} \cdot$ George P. Schmahl $^{1}$
}

Received: 30 September 2018/Accepted: 6 March 2019/Published online: 16 March 2019

(C) The Author(s) 2019

\begin{abstract}
East Flower Garden Bank (EFGB) and West Flower Garden Bank (WFGB), part of Flower Garden Banks National Marine Sanctuary (FGBNMS) in the northwestern Gulf of Mexico, support tropical coral reefs that exhibit over 50\% living coral cover. These reefs have been monitored annually since 1989, and in 2016 were exposed to higher than normal seawater temperatures leading to a severe bleaching event. Corals at EFGB and WFGB showed no signs of bleaching until September 2016, occurring later in the year compared to other reefs in the Caribbean region. Coral bleaching and subsequent recovery at each bank were documented through a time series of repetitive photographs within previously established long-term monitoring stations. Preceding the event, mean live coral cover within monitoring stations was collectively $64 \pm 2 \%$. Prior to signs of bleaching from July to September 2016, seawater temperatures on the reef were above $30{ }^{\circ} \mathrm{C}$ for a total of $36 \mathrm{~d}$ at EFGB and $21 \mathrm{~d}$ at WFGB. By October 2016, $67 \pm 5 \%$ of the coral cover
\end{abstract}

Topic Editor Morgan S. Pratchett

Electronic supplementary material The online version of this article (https://doi.org/10.1007/s00338-019-01788-7) contains supplementary material, which is available to authorized users.

Michelle A. Johnston

michelle.a.johnston@noaa.gov

1 NOAA Office of National Marine Sanctuaries, Flower Garden Banks National Marine Sanctuary, 4700 Avenue U, Bldg. 216, Galveston, TX 77551, USA

2 CPC Inc, 4700 Avenue U, Bldg. 216, Galveston, TX 77551, USA

3 Present Address: Harbor Branch Oceanographic Institute, Florida Atlantic University, 5600 US 1 North, Fort Pierce, FL 34946, USA within EFGB monitoring stations and $25 \pm 3 \%$ within WFGB monitoring stations exhibited signs of bleaching or paling stress, with dissimilarities in the amount of bleaching most likely due to significant differences in thermal profiles between banks. Significantly increasing long-term trends for daily mean seawater temperature indicate that temperatures on the banks have become warmer over time, and calculated bleaching threshold curves suggest that more than $50 \mathrm{~d}$ above $29.5^{\circ} \mathrm{C}$ would initiate a bleaching year at EFGB and WFGB. Even though recovery within monitoring stations at both banks was documented with no significant declines in mean coral cover from 2016 to 2017 (64\% and 62\%, respectively), it is likely FGBNMS will be subject to additional and more frequent bleaching events in the future as ocean temperatures continue to rise.

Keywords Bleaching - Coral - Gulf of Mexico · Monitoring $\cdot$ Temperature $\cdot$ Threshold

\section{Introduction}

East Flower Garden Bank (EFGB) and West Flower Garden Bank (WFGB), positioned approximately $20 \mathrm{~km}$ apart, are two of the three banks containing well-developed coral reefs that presently comprise Flower Garden Banks National Marine Sanctuary (FGBNMS) located in the northwestern Gulf of Mexico (Fig. 1). These reefs have developed on top of features formed by underlying salt domes, are located approximately $190 \mathrm{~km}$ south of the Texas-Louisiana border, and provide ideal conditions for colonization of Caribbean species of corals, sponges, invertebrates, macroalgae, and reef fish (Bright et al. 1984). The banks range in depth from 16 to $140 \mathrm{~m}$ and contain 


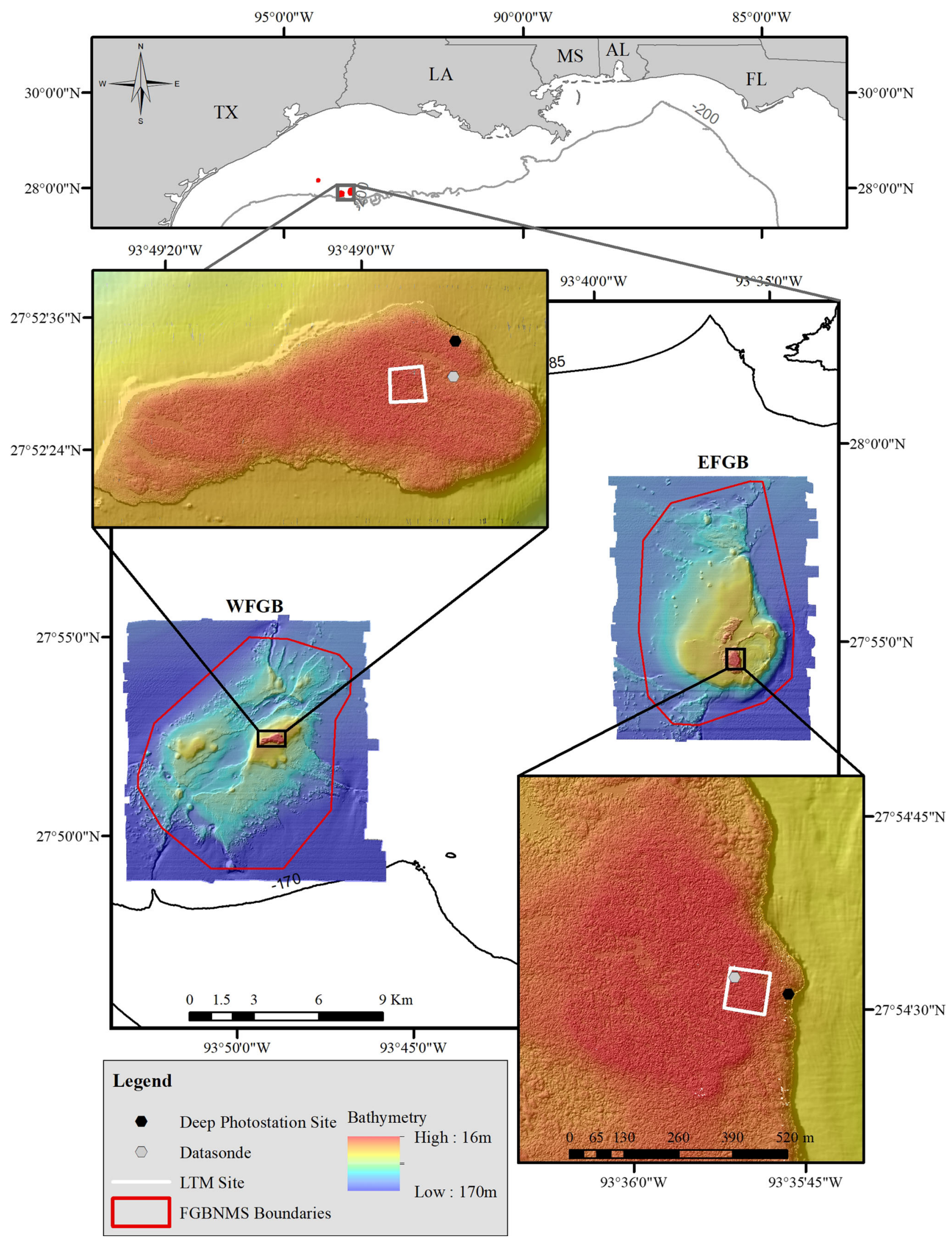


4Fig. 1 Bathymetric map of West Flower Garden Bank (WFGB) and East Flower Garden Bank (EFGB; boundaries outlined in red), located along the outer continental shelf in the Gulf of Mexico (top inset). The central reef cap area (depicted in red) supports habitat shallow enough for coral reef growth. Bathymetric map insets display $10,000 \mathrm{~m}^{2}$ long-term monitoring (LTM) study sites, deep photostation sites, and water quality datasonde (SBE 37) locations at both banks

several diverse habitats, with the shallow coral reef cap (16-46 m) harboring tropical hermatypic coral species (Bright et al. 1985; Schmahl et al. 2008; Johnston et al. 2016). Although the common coral species found at EFGB and WFGB are typical Caribbean reef species (predominantly Orbicella franksi and Pseudodiploria strigosa), the banks have relatively low species diversity: only 22 of over 60 western Atlantic and Caribbean region hermatypic coral species occur (Bright et al. 1984; Johnston et al. 2017). Shallow water octocorals are absent and scleractinian corals of the genus Acropora are exceedingly rare, likely due to the banks being at the northernmost latitudinal limit of the coral distribution range in the Gulf of Mexico (Bright et al. 1985; Aronson et al. 2005).

A federally supported annual long-term monitoring program has tracked specific areas of coral reef habitat atop EFGB and WFGB since 1989 (Johnston et al. 2016). Since the initiation of the monitoring program, mean living coral cover has remained near or above $50 \%$, despite declining coral cover in recent decades globally (Gardner et al. 2003; Jackson et al. 2014; Johnston et al. 2016). Due to their remote offshore location, relative inaccessibility, and depth, EFGB and WFGB have been relatively buffered from seawater temperature and salinity fluctuations, storm damage, and severe bleaching (Aronson et al. 2005; Johnston et al. 2016) that have impacted shallower, nearshore coral reefs worldwide (Altieri et al. 2017; Hughes et al. 2017, 2018). Mild to moderate bleaching has been documented at the banks in years past (i.e., 1990, 1995, $2005,2010)$ in association with prolonged seawater temperatures in excess of $30^{\circ} \mathrm{C}$; however, none of these events caused significant coral mortality or changes in overall mean percent coral cover (Hagman and Gittings 1992; CSA 1996; Precht et al. 2008; Eakin et al. 2010; Zimmer et al. 2010; Johnston et al. 2013).

In 2016, coral reefs globally were exposed to extreme seawater temperatures leading to severe bleaching events, most notably on the Great Barrier Reef (Ainsworth et al. 2016; Hughes et al. 2017; Monroe et al. 2018). This was the third global-scale event recorded since mass coral bleaching was first documented in the 1980s (Hughes et al. 2017). While bleaching in the Caribbean region was less severe than the Pacific region (Hughes et al. 2018), a significant bleaching event was documented at EFGB and
WFGB that began in late September 2016 directly associated with a sustained period of elevated seawater temperatures. This is the most severe bleaching event ever documented at EFGB and WFGB. Here, we describe benthic community parameters (including percent coral cover and colony counts) and seawater temperature data (Johnston et al. 2017) collected before, during, and after the event in order to examine levels of bleaching within monitoring stations in deep and shallow coral reef locations of FGBNMS. Long-term seawater temperature datasets were also utilized to estimate time-temperature bleaching threshold curves.

\section{Materials and methods}

\section{Study site description}

EFGB $\left(65.86 \mathrm{~km}^{2}\right)$ ranges in depth from 16 to $130 \mathrm{~m}$ and is situated approximately $193 \mathrm{~km}$ southeast of Galveston, Texas $\left(27^{\circ} 54.5 \mathrm{~N}, 93^{\circ} 36.0 \mathrm{~W}\right.$; Fig. 1). WFGB is located $172 \mathrm{~km}$ southeast of Galveston, Texas $\left(27^{\circ} 52.4 \mathrm{~N}\right.$, $93^{\circ} 48.8 \mathrm{~W}$; Fig. 1), and is slightly deeper $(18-140 \mathrm{~m})$ and larger in area $\left(77.54 \mathrm{~km}^{2}\right)$ than EFGB. Both banks are capped by a well-developed coral reef from 16 to $46 \mathrm{~m}$ covering $3.31 \mathrm{~km}^{2}$ at EFGB and $1.44 \mathrm{~km}^{2}$ at WFGB. Benthic percent cover data have been collected annually since 1989 within designated $10,000 \mathrm{~m}^{2}$ long-term monitoring study sites (herein referred to as LTM sites) atop EFGB and WFGB (Fig. 1). The EFGB LTM site ranges in depth from 17 to $27 \mathrm{~m}$ and is located on the eastern side of the central portion of the coral reef at EFGB (Fig. 1). The WFGB LTM site ranges in depth from 18 to $25 \mathrm{~m}$ and is located on the central portion of the reef at WFGB (Fig. 1). Within the LTM sites at each bank, approximately 40 repetitive photostations (secured to the reef substrate with pins marked by numbered tags ranging in depth from 18 to $24 \mathrm{~m}$ at EFGB and 20 to $24 \mathrm{~m}$ at WFGB) are photographed annually. It should be noted that the LTM sites at each bank were established in the late 1980s and were considered to be representative of the coral reef cap areas. Subsequent studies have documented that the coral community (percent cover and diversity) outside LTM sites and across the shallow coral cap is similar to the LTM sites (Dokken et al. 2003; Clark et al. 2014).

In addition, approximately 12 repetitive photostations have been established at monitoring sites along the sloping shelf at each bank for sampling the deeper reef community (i.e., 24-40 m; Fig. 1). The deep photostations at EFGB range in depth from 32 to $40 \mathrm{~m}$, and the deep photostations at WFGB range in depth from 24 to $38 \mathrm{~m}$ (Fig. 1). For clarity, the repetitive deep photostations along the sloping shelf will be referred to as "deep photostations" and the 
shallower repetitive photostations located within LTM sites will be referred to as "shallow photostations" from this point forward.

\section{Repetitive photostations}

As part of the annual long-term coral reef monitoring program, shallow and deep photostations were photographed at EFGB in July 2016 and WFGB in August 2016 prior to signs of bleaching. After initial observations of bleached corals were made in September 2016, shallow and deep photostations were photographed again in October 2016. Shallow and deep photostations at EFGB were photographed once more in January 2017 (stations at WFGB were not photographed due to time constraints and unfavorable offshore conditions), and shallow and deep photostations were photographed in August 2017 at both banks during annual long-term monitoring operations to determine percent coral cover and varying levels of recovery or decline from bleaching. A total of 37 shallow photostations were photographed at EFGB and 41 were photographed at WFGB in 2016 and 2017. For the deep photostations, 11 photostations were photographed at EFGB, and 12 stations were photographed at WFGB. It should be noted that photostations established as part of the long-term monitoring program were not intended to provide a comprehensive view of coral cover within the EFGB and WFGB LTM sites, as they were selectively placed on sites of interest in order to monitor individual corals and species interactions over time.

All shallow and deep photostations were photographed using a Nikon ${ }^{\circledR}$ D7000 ${ }^{\circledR}$ DSLR camera with 16-mm lens in Sea\&Sea ${ }^{\circledR}$ housing with Sea\&Sea ${ }^{\circledR}$ NX compact dome port and two Inon ${ }^{\circledR} \mathrm{Z} 240$ strobes (Johnston et al. 2017). The camera, mounted in the center of an aluminum T-shaped camera frame at a distance of $2 \mathrm{~m}$ from the substrate, produced images covering $5 \mathrm{~m}^{2}$. To ensure that the stations were photographed in the same manner each year, the frame was oriented in a north-facing direction using a compass and kept vertical using an attached bulls-eye bubble level.

Mean percent benthic cover and the percentage of bleached coral cover within shallow and deep photostations were determined by analyzing images using Coral Point Count with Microsoft ${ }^{\circledR}$ Excel $^{\circledR}$ extensions v4.1 (CPCe; Kohler and Gill 2006) with a 100 random point overlay distributed on each station photograph. Organisms positioned beneath each random point were identified to the lowest possible taxonomic level, and grouped into primary functional groups: (1) coral, (2) sponge, (3) macroalgae, (4) sand, and (5) colonizable substrate, a composite substrate category that included crustose coralline algae, fine turf algae, and bare rock (Aronson and Precht 2000; Aronson et al. 2005). Macroalgae included algae longer than approximately $3 \mathrm{~mm}$ and thick algal turfs covering underlying substrate. The incidence of coral paling and bleaching was also noted for all coral points. Any point that landed on coral that was pale or discolored relative to what was considered normal for the species was characterized as "paling" coral, and any point that landed on a portion of coral with bright white polyp tissue was characterized as "bleached" (Lang et al. 2012). Point count analysis was conducted for each photostation image, and mean percent cover for all groups was determined by averaging photostations by depth and bank. Results are presented as mean percent cover \pm standard error.

Benthic percent coral cover data were evaluated with nonparametric distance-based analyses $\left(\right.$ Primer $^{\circledR}$ version 7.0, Plymouth, UK). Euclidean distance resemblance matrices were calculated using untransformed percent cover data for both shallow and deep photostations. Data were left untransformed so the significance of non-dominant groups was not overinflated. Permutational multivariate analysis of variance (PERMANOVA) was based on resemblance matrices and used to test for benthic coral cover differences and estimate components of variation between EFGB and WFGB shallow and deep photostations from 2016 to 2017 (Anderson et al. 2008; Clarke et al. 2014).

Additionally, to assess impacts to specific coral colonies from bleaching stress in the photostations, total coral colonies in each photostation image were counted, and binned as to the degree of bleaching impact. For each coral colony, an assessment was made to characterize the entire colony as bleached, paling or unbleached. Total percent of bleached and paling coral colonies were calculated to determine the percent of colonies affected per bank. Similarly, percent of species affected per station were calculated at EFGB and WFGB.

\section{Water temperature}

As part of the FGBNMS long-term monitoring program, water quality instrumentation was present at EFGB and WFGB before, during, and after the bleaching event. The primary datasonde for recording hourly seawater temperature at depth on the reefs (approximately $22 \mathrm{~m}$ at EFGB and $28 \mathrm{~m}$ at WFGB) was a Sea-Bird Electronics 37 MicroCAT recorder (Sea-Bird Electronics, Bellevue, WA; herein referred to as SBE 37) with Onset ${ }^{\circledR}$ Computer Corporation $\mathrm{HOBO}^{\circledR}$ Pro v2 U22-001 thermographs (herein referred to as $\mathrm{HOBO}$ ) attached to the SBE 37 instruments for redundancy (Johnston et al. 2017). HOBOs were also deployed at $30 \mathrm{~m}$ and $40 \mathrm{~m}$ deep photostation depths at EFGB and WFGB to record hourly temperature. Seawater temperatures have been monitored on the banks 
since 1990 as part of the long-term monitoring program (Johnston et al. 2017).

Daily mean 2016 seawater temperature data from SBE 37 instruments were compared by bank and also to the historic long-term monitoring daily mean dataset (1990-2015) using a paired $t$ test in $\mathrm{R}^{\circledR} \mathrm{v} 2.13 .2$ (R Core Team 2012). Monotonic trends over the course of the longterm dataset (1990-2016) were detected using the Seasonal-Kendall trend test (Helsel and Hirsch 2002; Helsel et al. 2006). The Seasonal-Kendall trend test performed the Mann-Kendall trend test for each month and evaluated changes among the same months from different years over time, accounting for serial correlation in repeating seasonal patterns.

To estimate time-temperature bleaching threshold curves (Berkelmans 2002; Manzello et al. 2007) at EFGB and WFGB, daily mean seawater temperature data at depth from 2009 to 2016 were examined, tallying days averaging $29{ }^{\circ} \mathrm{C}$ in 0.1 -degree ${ }^{\circ} \mathrm{C}$ increments up to $31{ }^{\circ} \mathrm{C}$. Total days at each temperature increment were summed for both bleaching and non-bleaching years, and bleaching thresholds for each bank based on exposure time (number of days above high temperatures) during bleaching years were estimated and interpolated as polynomial bleaching curves for each bank. Data from 2009 to 2016 were utilized because there were no gaps in seawater temperature data, and 2010 and 2016 were documented bleaching years at EFGB and WFGB based on a posteriori FGBNMS data.

\section{Results}

Seawater temperatures on the reefs at EFGB and WFGB were higher than average in 2016, corresponding to a bleaching event at both banks. The SBE 37 instrument on the reef at EFGB logged a total of $36 \mathrm{~d}$ above $30{ }^{\circ} \mathrm{C}$ from July 23 to September 21, 2016, and the SBE 37 instrument on the WFGB reef logged a total of $21 \mathrm{~d}$ above $30{ }^{\circ} \mathrm{C}$ from July 23 to September 21, 2016 (Fig. 2a). This in situ data correlated with sea surface temperature satellite data as described by NOAA's Coral Reef Watch bleaching alerts in 2016 for EFGB and WFGB, which reported a maximum heat stress of $9.7{ }^{\circ} \mathrm{C}$-weeks from September 13 to 18,2016 (NOAA Coral Reef Watch 2017).

When compared by bank, SBE 37 mean daily seawater temperature at EFGB was significantly warmer than WFGB in 2016 ( $t$ test, $d f=365, t=9.82, \mathrm{p}<0.002$ ). Plotted against a 25-yr mean (1990-2015), seawater temperatures on the EFGB reef in 2016 were higher than the 25-yr mean for 345 of $365 \mathrm{~d}$ and were significantly warmer ( $t$ test, $d f=365, t=33.97, p<0.002$ ) than the 25-yr mean (Fig. 2a). At WFGB, temperatures on the reef in 2016 were higher than the 25-yr mean for 307 of $365 \mathrm{~d}$ and were significantly warmer $(t$ test, $d f=365, \quad t=22.20$, $p<0.002$ ) than the $25-y r$ mean (Fig. 2a). Such prolonged, elevated temperatures as recorded in 2016 were not exhibited in any other year from 1990 to 2015. When examining daily mean seawater temperature long-term trends, the Seasonal-Kendall test resulted in a significantly increasing monotonic trend from 1990 to 2016 at EFGB and WFGB, after adjusting for correlation among seasons $(\tau=0.29, \quad z=5.48, \quad p=0.004$ and $\tau=0.24, z=4.87$, $p=0.007$, respectively), suggesting that seawater temperatures on the banks have increased since 1990 .

At the deep photostations, HOBO loggers also detected warm seawater temperatures in 2016 (Fig. 2b, c). At EFGB, there were $15 \mathrm{~d}$ above $30{ }^{\circ} \mathrm{C}$ recorded by the $30 \mathrm{~m}$ logger and zero days above $30{ }^{\circ} \mathrm{C}$ at the $40 \mathrm{~m} \mathrm{HOBO}$, clearly displaying cooler temperatures at depth. In contrast, at WFGB, there were $10 \mathrm{~d}$ logged above $30{ }^{\circ} \mathrm{C}$ at the $30 \mathrm{~m}$ HOBO and $24 \mathrm{~d}$ above $30^{\circ} \mathrm{C}$ at the $40 \mathrm{~m}$ HOBO.

In July and August 2016 before major signs of bleaching occurred, mean coral cover in the EFGB and WFGB shallow photostations was greater than $60 \%$, with less than $0.2 \%$ of the coral cover analyzed showing incidences of bleaching and paling (Table 1). Based on CPCe benthic cover analysis from photographs taken in October 2016, $67.35 \pm 4.53 \%$ of the coral cover within the EFGB shallow photostations exhibited signs of bleaching and paling stress, with $21.33 \pm 2.01 \%$ of the coral cover appearing to be completely bleached (Table 1; Fig. 3). Within the WFGB shallow photostations, $25.30 \pm 3.40 \%$ of the coral cover exhibited bleaching and paling stress, with $8.81 \pm 1.79 \%$ of the coral cover appearing to be fully bleached (Table 1).

When assessing bleaching based on coral colony counts from shallow photostation images, 756 individual colonies out of 1626 total colonies (46\%) within the EFGB shallow photostations exhibited signs of bleaching and paling stress, with $24 \%$ of the colonies appearing to be completely or partially bleached (Supplementary Table 1). At WFGB, 500 colonies out of 2051 total colonies (24\%) within shallow photostations exhibited signs of bleaching and paling stress, with $10 \%$ of the colonies appearing to be completely or partially bleached (Supplementary Table 1). Based on both the CPCe percent cover estimates and individual coral colony counts, the EFGB shallow photostations contained higher bleached coral cover and a higher percentage of bleached colonies than the WFGB photostations.

In 2016, 18 species of coral were identified in the shallow photostations. Based on total colony counts, $O$. franksi was the coral species that was observed to most frequently bleach or pale (Fig. 4), due to the fact that $O$. franksi is the dominant reef-building coral at EFGB and WFGB. Therefore, to further investigate susceptible 
Fig. 2 Daily mean seawater temperature $\left({ }^{\circ} \mathrm{C}\right)$ from EFGB and WFGB SBE instruments in 2016 and the 25-yr daily mean from an approximate $24 \mathrm{~m}$ depth (a), 30 m HOBOs in 2016 (b), and $40 \mathrm{~m}$ HOBOs in 2016 (c). Gray line is at $30{ }^{\circ} \mathrm{C}$, often considered a bleaching threshold
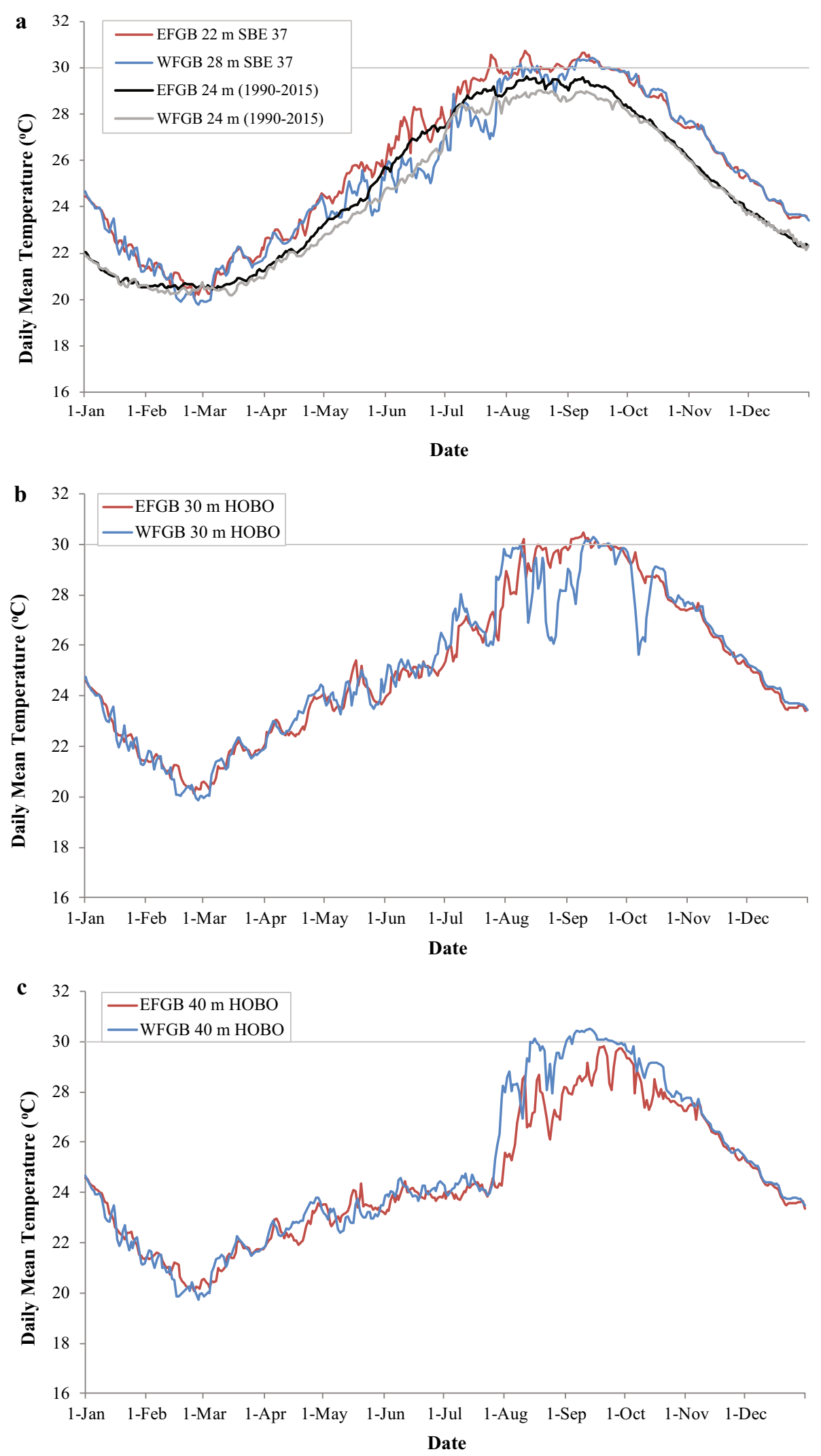

species, the percent of each individual species to bleach or pale based on total colony counts for that species was ranked, resulting in Millepora alcicornis and Montastraea cavernosa as the predominant species most susceptible to 
Table 1 Mean percent coral cover and percent coral cover to bleach and/or pale at EFGB and WFGB shallow and deep photostations in 2016 and 2017
Fig. 3 Time series of EFGB shallow photostation \#102 (ad). Healthy coral colonies in July 2016 (a), bleached and paling corals in October 2016 (b), recovering corals with minimal paling in January 2017 (c), fully recovered coral colonies in August 2017 (d)

\begin{tabular}{|c|c|c|c|c|}
\hline & July/August 2016 & October 2016 & January 2017 & August 2017 \\
\hline \multicolumn{5}{|c|}{ EFGB shallow photostations (18-24 m) } \\
\hline Coral cover $(\%)$ & $62.23 \pm 2.77$ & $63.99 \pm 2.37$ & $62.11 \pm 2.52$ & $62.55 \pm 2.86$ \\
\hline Bleaching $(\%)$ & $0.00 \pm 0.00$ & $21.33 \pm 2.01$ & $0.52 \pm 0.35$ & $0.14 \pm 0.14$ \\
\hline Paling $(\%)$ & $0.15 \pm 0.11$ & $46.02 \pm 2.52$ & $12.40 \pm 2.14$ & $1.08 \pm 0.57$ \\
\hline Total bleaching/paling (\%) & $0.15 \pm 0.11$ & $67.35 \pm 4.53$ & $12.92 \pm 2.49$ & $1.22 \pm 0.70$ \\
\hline \multicolumn{5}{|c|}{ WFGB shallow photostations (20-24 m) } \\
\hline Coral cover $(\%)$ & $65.06 \pm 2.02$ & $62.04 \pm 1.92$ & NA & $61.67 \pm 1.89$ \\
\hline Bleaching $(\%)$ & $0.04 \pm 0.04$ & $8.81 \pm 1.79$ & NA & $0.00 \pm 0.00$ \\
\hline Paling $(\%)$ & $0.09 \pm 0.06$ & $16.49 \pm 2.11$ & NA & $0.76 \pm 0.44$ \\
\hline Total bleaching/paling (\%) & $0.13 \pm 0.10$ & $25.30 \pm 3.90$ & NA & $0.76 \pm 0.44$ \\
\hline \multicolumn{5}{|c|}{ EFGB deep photostations $(32-40 \mathrm{~m})$} \\
\hline Coral cover $(\%)$ & $72.61 \pm 3.62$ & $71.66 \pm 4.38$ & $73.59 \pm 4.41$ & $72.44 \pm 3.64$ \\
\hline Bleaching $(\%)$ & $0.00 \pm 0.00$ & $0.55 \pm 0.31$ & $0.24 \pm 0.24$ & $0.00 \pm 0.00$ \\
\hline Paling $(\%)$ & $3.17 \pm 2.24$ & $28.74 \pm 4.23$ & $2.25 \pm 1.58$ & $0.75 \pm 0.44$ \\
\hline Total bleaching/paling (\%) & $3.17 \pm 2.24$ & $29.29 \pm 4.54$ & $2.49 \pm 1.82$ & $0.75 \pm 0.44$ \\
\hline \multicolumn{5}{|c|}{ WFGB deep photostations (24-38 m) } \\
\hline Coral cover $(\%)$ & $75.84 \pm 3.90$ & $72.36 \pm 5.04$ & NA & $73.53 \pm 4.59$ \\
\hline Bleaching $(\%)$ & $0.00 \pm 0.00$ & $4.74 \pm 2.91$ & NA & $0.00 \pm 0.00$ \\
\hline Paling $(\%)$ & $0.00 \pm 0.00$ & $10.63 \pm 2.68$ & NA & $0.00 \pm 0.00$ \\
\hline Total bleaching/paling (\%) & $0.00 \pm 0.00$ & $15.37 \pm 5.60$ & NA & $0.00 \pm 0.00$ \\
\hline
\end{tabular}
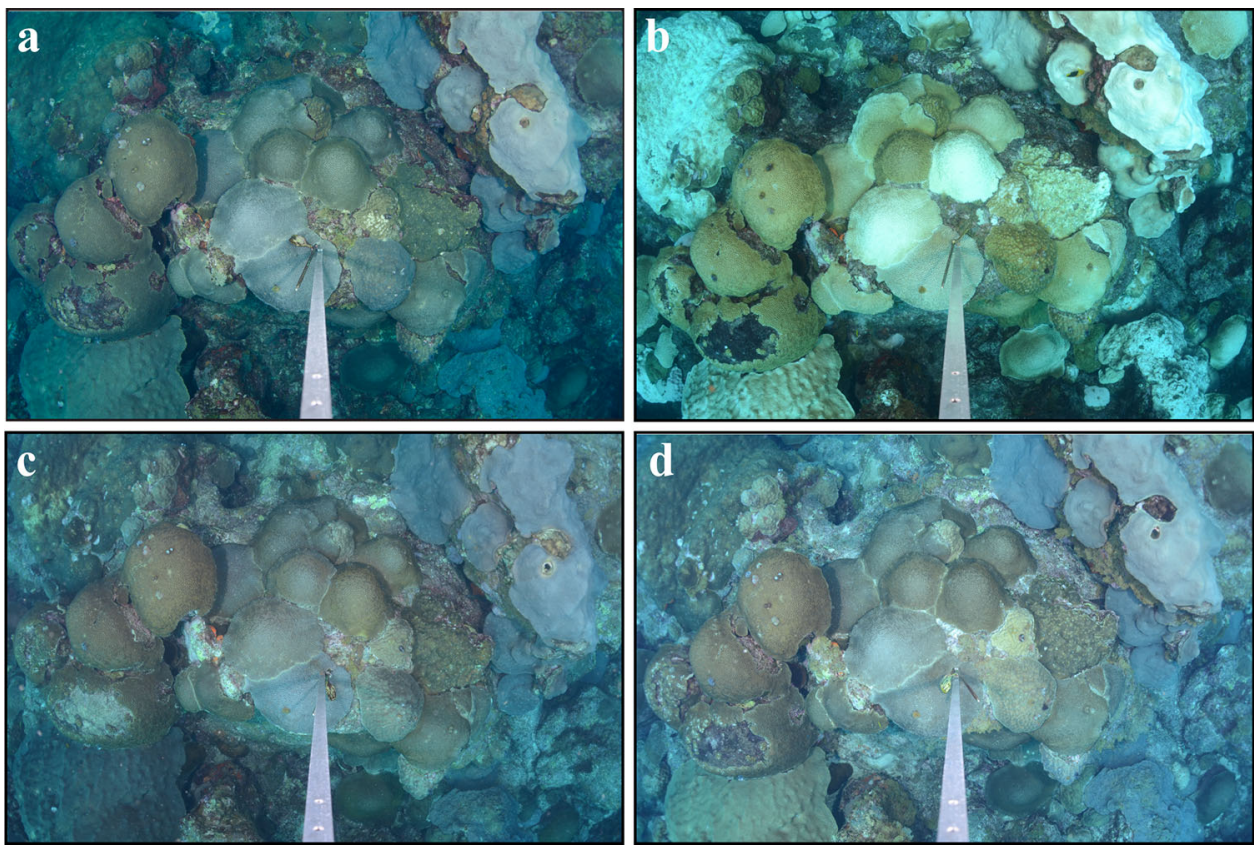

bleaching stress at EFGB and WFGB shallow photostations (Fig. 4).

While still apparent, percent cover affected by bleaching and paling was less in the deep photostations than in the shallow photostations in October 2016. In the EFGB deep photostations, $29.29 \pm 4.54 \%$ of the coral cover was bleached and paled, with $0.55 \pm 0.31 \%$ of the coral cover appearing to be completely bleached (Table 1). In the
WFGB deep photostations, $15.37 \pm 5.60 \%$ of the coral cover was bleached and paled, with $4.74 \pm 2.91 \%$ of the coral cover appearing to be completely bleached (Table 1). Based on coral colony counts within the deep photostations, 46 colonies out of 294 total colonies (16\%) at the EFGB deep photostations exhibited signs of bleaching and paling stress, with $4 \%$ of the colonies appearing to be completely or partially bleached (Supplementary Table 1). 

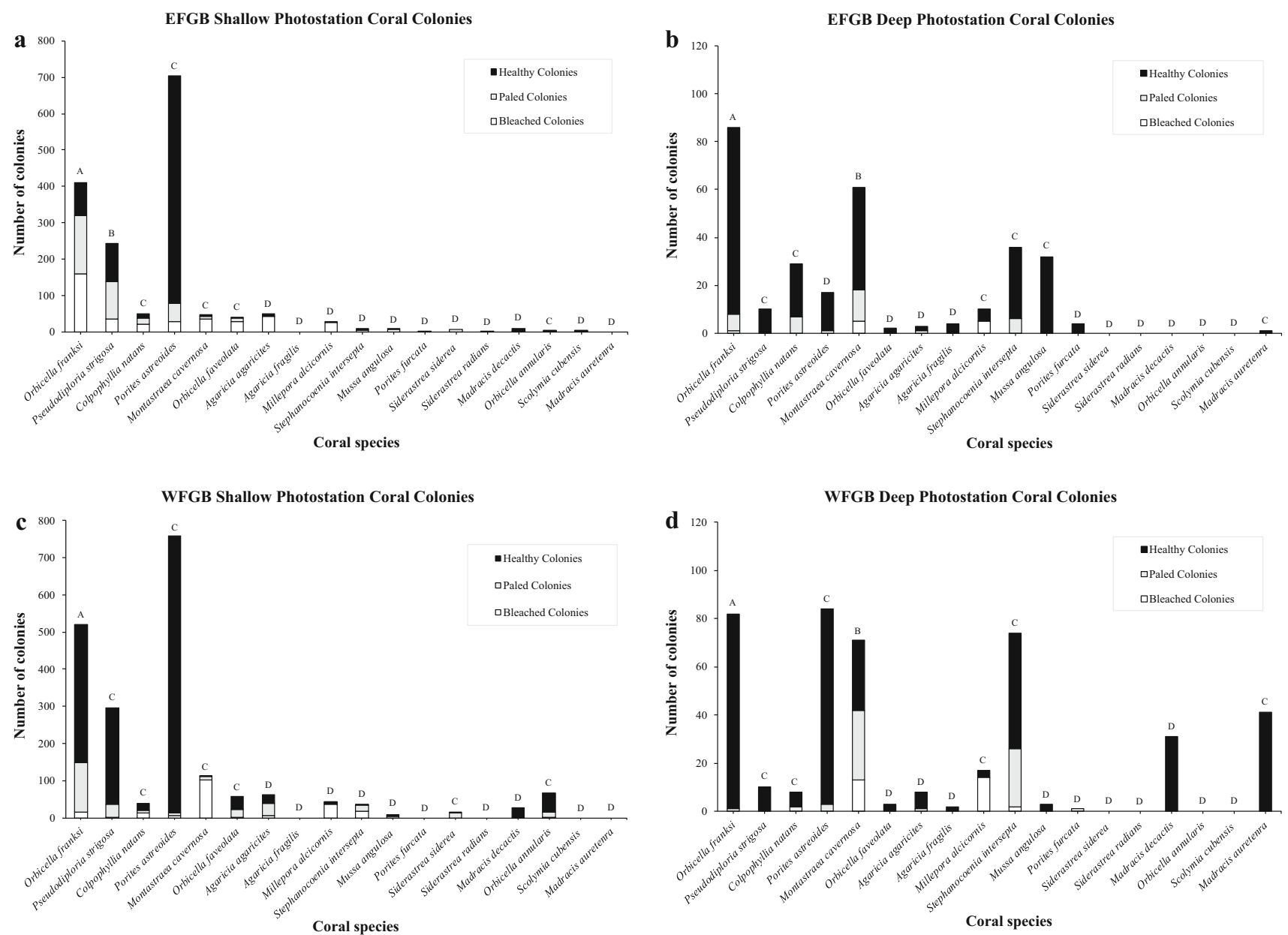

Fig. 4 Number of colonies that were bleached, paled, or healthy at EFGB shallow photostations ( $n=37$; total area of $185 \mathrm{~m}^{2}$ ) (a), EFGB deep photostations ( $n=11$; total area of $\left.55 \mathrm{~m}^{2}\right)(\mathbf{b})$, WFGB shallow photostations $\left(n=41\right.$, total area of $\left.205 \mathrm{~m}^{2}\right)(\mathbf{c})$, and WFGB deep photostations $\left(n=12\right.$, total area of $\left.60 \mathrm{~m}^{2}\right)(\mathbf{d})$ in October 2016.

At the WFGB deep photostations, 91 colonies out of 445 total colonies (20\%) exhibited signs of bleaching and paling stress, with $7 \%$ of the colonies appearing to be completely or partially bleached (Supplementary Table 1). Similar to the shallow photostations, M. cavernosa and $M$. alcicornis were the species most susceptible to bleaching stress at the deep photostations (Fig. 4).

By the end of January 2017, seawater temperatures surrounding the banks had cooled to $22{ }^{\circ} \mathrm{C}$ (Fig. 2) and signs of coral paling and bleaching had subsided. After assessing data collected in January 2017, CPCe benthic cover analysis resulted in only $12.92 \pm 2.49 \%$ of the coral cover within the EFGB shallow photostations still exhibiting signs of bleaching and paling stress, with $0.52 \pm 0.35 \%$ of the coral cover still appearing to be completely bleached (Table 1). Minimal mortality was observed $(0.35 \pm 0.32 \%)$ based on the EFGB CPCe percent cover analysis. Based on colony counts in EFGB

Letters above bars (A-D) indicates coral cover, where group A represents coral cover $\geq 25 \%$, group B represents coral cover $<25$ to $\geq 10 \%$, group $\mathrm{C}$ represents coral cover $<10$ to $\geq 1 \%$, and group $\mathrm{D}$ represents coral cover $<1 \%$

shallow photostation images in January 2017, 63 individual colonies were still exhibiting signs of paling (3.88\% of all counted colonies), 62 colonies exhibited signs of partial mortality where part of the colony had died $(3.81 \%$ of colonies), and 25 colonies succumbed to mortality (1.54\% of colonies), primarily represented by $M$. alcicornis. The results of both the percent coral cover and colony count analyses suggested that the majority of the colonies had reestablished their endosymbiotic algae communities (family Symbiodiniaceae) and recovered (Fig. 3c).

At EFGB deep photostations, CPCe benthic cover analysis resulted in only $2.49 \pm 1.82 \%$ of coral cover still exhibiting signs of bleaching and paling stress, with $0.24 \pm 0.24 \%$ of coral cover still appearing to be completely bleached (Table 1). When further examining specific colonies, two colonies were still exhibiting signs of bleaching $(0.68 \%$ of all counted colonies), 12 colonies were still exhibiting signs of paling (4.08\% of colonies), 
and one colony exhibited signs of partial mortality $(0.34 \%$ of colonies). No complete colony mortality was observed. WFGB shallow and deep photostations were not photographed in January 2017 due to time and weather constraints, but signs of coral paling and bleaching had subsided based on diver observations.

One year later, during annual long-term monitoring data collection in August 2017, mean living coral cover remained above $60 \%$ within shallow photostations at both banks. Mean coral cover was $62.55 \pm 2.86 \%$ within the EFGB shallow photostations and $61.67 \pm 1.89 \%$ within the WFGB shallow photostations (Table 1). When comparing percent cover between years, benthic percent coral cover in 2017 was not significantly different from cover in the 2016 shallow photostations at either bank. Similarly, mean percent living coral cover in 2017 at the deep photostations was not significantly different from coral cover at the deep photostations in 2016 at either bank. Mean coral cover was $72.44 \pm 3.64 \%$ in the EFGB deep photostations in August 2017 and $73.53 \pm 4.59 \%$ in the WFGB deep photostations (Table 1).

When examining bleaching threshold curves for each bank (Berkelmans 2002; Manzello et al. 2007), the thermal stress indices calculated were able to effectively segregate bleaching years (2010 and 2016) from non-bleaching years at EFGB and WFGB, as bleaching depended both on temperature and exposure time at that temperature (number of days above high temperatures; Fig. 5). At EFGB a total of $27.5 \mathrm{~d}$ or more above $30{ }^{\circ} \mathrm{C}$ would result in coral bleaching (as seen in 2016), whereas a total of $57.5 \mathrm{~d}$ above $29.6{ }^{\circ} \mathrm{C}$ or a total of $79 \mathrm{~d}$ above $29{ }^{\circ} \mathrm{C}$ would also result in coral bleaching based on calculated thresholds. At WFGB, the threshold was slightly less, where a total of $21 \mathrm{~d}$ or more above $30^{\circ} \mathrm{C}$ would result in coral bleaching (as seen in 2016) or a total of $52.5 \mathrm{~d}$ above $29.5^{\circ} \mathrm{C}$ and a total of $71 \mathrm{~d}$ above $29^{\circ} \mathrm{C}$ would result in coral bleaching. Overall, the data suggest that more than $50 \mathrm{~d}$ above $29.5^{\circ} \mathrm{C}$ could initiate a bleaching year at either EFGB or WFGB (Fig. 5).

\section{Discussion}

While coral bleaching was observed at both banks in 2016, significant dissimilarities in the amount of bleaching at EFGB compared to WFGB were likely due to the significant differences in seawater temperatures at depth surrounding the banks (Fig. 2). On the EFGB reef, there were more days above $30{ }^{\circ} \mathrm{C}$ (36) than at WFGB (21), and subsequently, more bleaching. Bleaching was less in the deep photostations, as seawater temperatures at these deeper depths are usually cooler along the sloping shelf than the central portion of the reef where the shallow photostations are located; however, the $40 \mathrm{~m} \mathrm{HOBO}$ at WFGB was anomalous in that it logged more days above $30{ }^{\circ} \mathrm{C}$ than the WFGB $30 \mathrm{~m}$ HOBO. While the shallow photostations at WFGB are slightly deeper than the EFGB shallow photostations, the differences in temperature are more likely associated with oceanographic influences, as circulation patterns can be highly variable even within limited spatial scales in the northern Gulf of Mexico, and water flow and mixing can be highly dependent on the strength and current direction across a bank (Jarosz et al. 2014; Muller-Karger et al. 2015). In 2016, differences in sea surface temperature, surface salinity, and chlorophyll were confirmed through remote sensing and satellite imagery, as a plume of coastal water was present over EFGB from July to August 2016 (IMaRS 2018; TABS 2018), which may have influenced EFGB more than WFGB.

The two different methods used to investigate bleaching yielded slightly different results; however, both the CPCe percent cover estimates and individual coral colony counts concurred that EFGB had a higher incidence of bleaching than WFGB. Since the incidence of bleaching has been reported in various ways in previous studies, we found it useful to compare two common approaches (percent coral cover and colony counts) utilizing this photo method. Conducting CPCe percent cover estimates allowed for an overall bleaching estimate within the photostations, while conducting individual colony counts allowed for further investigation of impacts at the species level. While the methods are different, they were both effective at estimating bleaching, and due to the versatile nature of the photostations used in the FGBNMS long-term monitoring program, both methods were able to be utilized to track corals over time. It should be noted that bleaching impacts were only assessed in the long-term monitoring photostations ( $<1 \%$ of the coral cap) as opposed to surveys conducted across the entire reef cap.

In general, it has been proposed that the bleaching threshold for many coral reefs is $30{ }^{\circ} \mathrm{C}$ (Coles et al. 1976), including the FGBNMS (Hagman and Gittings 1992). Even though bleaching events have been reported at FGBNMS in the past, these events have not resulted in significant coral mortality (Gittings et al. 1992; Hagman and Gittings 1992; CSA 1996; Dokken et al. 1999, 2001, 2003; Precht et al. 2006; Eakin et al. 2010; Zimmer et al. 2010; Johnston et al. 2013, 2015). From 1990 to 1994, minor occurrences of coral bleaching were documented in individual colonies in shallow photostations at EFGB and WFGB (Hagman and Gittings 1992; CSA 1996); however, 1995 was the first moderate bleaching event documented at the banks (approximately $3 \%$ of all coral cover bleached) coinciding with seawater temperatures above $30^{\circ} \mathrm{C}$ (CSA 1996). Similar to the observations in 2016, M. cavernosa and $M$. alcicornis were the species most affected by bleaching in 
Fig. 5 Bleaching threshold curves for EFGB (a), WFGB (b), and EFGB and WFGB curves combined, based on daily mean seawater temperature $\left({ }^{\circ} \mathrm{C}\right)$ at depth $(24 \mathrm{~m})$ and exposure time (number of days). Trend lines for bleaching years displayed in red and nonbleaching years in black. Estimated bleaching curve in blue
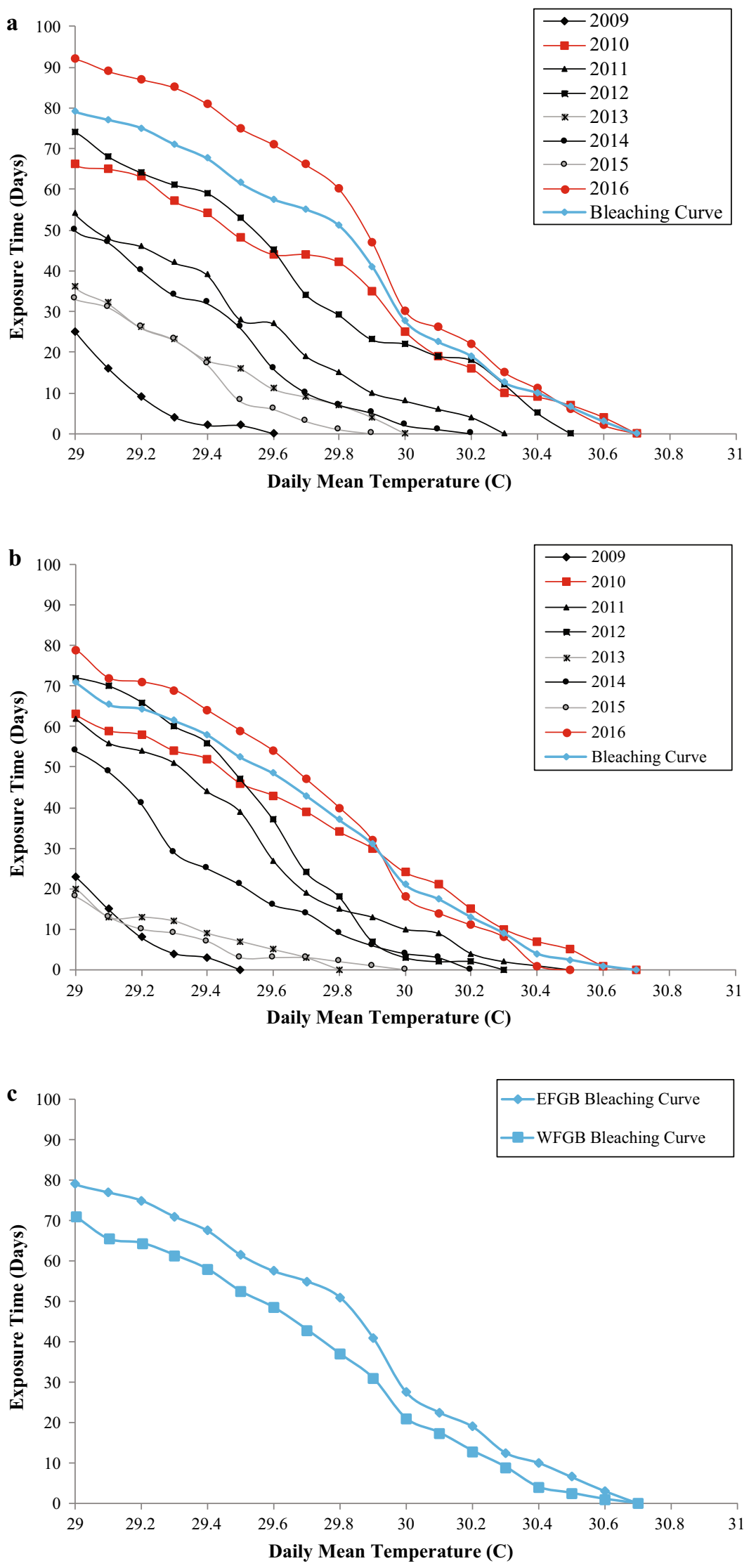
1995 , and post-bleaching mortality rates were low at $0.2 \%-$ $2.8 \%$ (CSA 1996).

In 2005 , elevated seawater temperatures above $30{ }^{\circ} \mathrm{C}$ were recorded for $29 \mathrm{~d}$ at EFGB and $7 \mathrm{~d}$ at WFGB, with moderate to severe coral bleaching documented throughout the Caribbean region, including moderate bleaching at EFGB and WFGB, due to warm ocean temperatures (Eakin et al. 2010; Zimmer et al. 2010). A series of surveys in 2005 at EFGB documented 10\% coral bleaching (from percent cover random point count analysis) in shallow photostations (Precht et al. 2008). However, subsequent sampling in 2006 demonstrated no significant mortality from this event. Higher than average seawater temperatures were also observed during the late summer months of 2010, exceeding $30{ }^{\circ} \mathrm{C}$ for $25 \mathrm{~d}$ at EFGB and $24 \mathrm{~d}$ at WFGB (Johnston et al. 2013). Significant bleaching occurred throughout the region in 2010, including EFGB and WFGB, but was not reflected within the long-term monitoring dataset as signs of bleaching did not manifest until late fall in 2010, after monitoring data was collected. This is similar to all known bleaching events at EFGB and WFGB, where bleaching did not manifest on the banks until later in the year (September/October), as compared to most other areas in the Caribbean. For this reason, it is difficult to assess the full history of coral bleaching at FGB due to the fact that annual monitoring surveys are typically in conducted prior to the time of bleaching onset during optimal weather conditions before the height of hurricane season. For example, in Hughes et al. (2018), EFGB and WFGB were not locations in the Gulf of Mexico and Caribbean region documented to bleach because the cutoff for data gathering was September 2016 (when corals at the banks were only beginning to show signs of bleaching). As seen in the 2016 percent coral cover data, bleaching in the EFGB and WFGB shallow photostations was less than $1 \%$ in July and August 2016, not becoming more severe until later in the season, as documented in October 2016.

In 2016, corals in many regions around the world were exposed to extreme seawater temperatures leading to a severe bleaching event (Hughes et al. 2017, 2018), with the Great Barrier Reef and other areas in the Pacific experiencing significant bleaching mortality. While bleaching in the Caribbean was not as extreme as in the Pacific, many Caribbean coral reefs still experienced severe to moderate bleaching (Hughes et al. 2018). Even though coral at EFGB and WFGB experienced the highest levels of bleaching ever recorded at these banks, post-bleaching mortality rates were low, with the majority of coral colonies recovering after seawater temperatures dropped below threshold levels. While threshold temperatures of approximately $30{ }^{\circ} \mathrm{C}$ may be representative of western Atlantic and Caribbean reefs (Ogden and Wicklund 1988; Hagman and Gittings 1992; Manzello et al. 2007), bleaching at
FGBNMS may begin at temperatures less than $30^{\circ} \mathrm{C}$, as shown in the threshold curves, if exposure time is prolonged. Fortunately, EFGB and WFGB have, to date, recovered from documented bleaching events, but more investigation is needed to determine mortality thresholds at the banks (Berkelmans 2009). Nevertheless, the fact that the comparatively deep reefs at EFGB and WFGB experience more stable conditions than shallower tropical coral reefs, apparently resulting in reduced effects when bleaching occurs, suggest that local conditions (e.g., remoteness, depth, fewer stressors) are a key driver in bleaching susceptibility and recovery.

Climate model projections suggest that frequency of bleaching will continue to increase in the future (Ateweberhan et al. 2013; Heron et al. 2016; von Hooidonk et al. 2016; Hughes et al. 2018). Coral scientists agree that increased frequency and severity of coral bleaching events are correlated with elevated seawater temperatures driven by climate change (Baker et al. 2008; Hughes et al. 2018). Many also recognize that as ocean temperatures continue to rise, certain corals may be found to be more resistant than others (Baker et al. 2008; Mumby and Steneck 2011). Monitoring at FGBNMS contributes significantly to research programs, as multi-decadal temperature records at depth track long-term trends, and repetitive monitoring stations allow researchers to track individual corals over time, including during extreme events, such as those related to bleaching. As the global ocean environment changes over time, including changing conditions in the Gulf of Mexico (Karnauskas et al. 2015), continued monitoring will be essential to documenting ecosystem change and to understanding other factors that drive shifts and disturbances.

Acknowledgements We thank the United States Department of Interior's Bureau of Ocean Energy Management (BOEM) and the National Marine Sanctuary Foundation for supporting the FGBNMS long-term monitoring program, scientific divers from Texas A\&M University at Galveston and Moody Gardens Aquarium for assisting with fieldwork, the crew of the $R / V$ Manta, the NOAA Dive Center, Dr. Frank Muller-Karger and Dr. Daniel Otis from the University of South Florida, and Dr. Mikhail V. Matz from the University of Texas at Austin. We also thank the anonymous referees for their insightful comments. Fieldwork was conducted under permit: FGBNMS-2014001.

\section{Compliance with ethical standards}

Conflict of interest On behalf of all authors, the corresponding author states that there is no conflict of interest.

Open Access This article is distributed under the terms of the Creative Commons Attribution 4.0 International License (http://creative commons.org/licenses/by/4.0/), which permits unrestricted use, distribution, and reproduction in any medium, provided you give appropriate credit to the original author(s) and the source, provide a link to the Creative Commons license, and indicate if changes were made. 


\section{References}

Ainsworth TD, Heron SF, Ortiz JC, Mumby PJ, Grech A, Ogawa D, Eakin CM, Leggat W (2016) Climate change disables coral bleaching protection on the Great Barrier Reef. Science 352:338-342

Altieri AH, Harrison SB, Seemann J, Collin R, Diaz RJ, Knowlton N (2017) Tropical dead zones and mass mortalities on coral reefs. Proc Natl Acad Sci 114:3660-3665

Anderson M, Gorley R, Clarke K (2008) PERMANOVA + for PRIMER: guide to software and statistical methods. PRIMER-E Ltd, Plymouth

Aronson RB, Precht WF (2000) Herbivory and algal dynamics on the coral reef at Discovery Bay, Jamaica. Limnol Oceanogr 45:251-255

Aronson RB, Precht WF, Murdoch TJT, Robbart ML (2005) Longterm persistence of coral assemblages on the Flower Garden Banks, Northwestern Gulf of Mexico: implications for science and management. Gulf Mex Sci 23:84-94

Ateweberhan M, Feary DA, Keshavmurthy S, Chen A, Schleyer MH, Sheppard CRC (2013) Climate change impacts on coral reefs: Synergies with local effects, possibilities for acclimation, and management implications. Mar Pollut Bull 74:526-539

Baker AC, Glynn PW, Riegl B (2008) Climate change and coral reef bleaching: An ecological assessment of long-term impacts, recovery trends and future outlook. Estuar Coast Shelf Sci 80:435-471

Berkelmans R (2002) Time-integrated thermal bleaching thresholds of reefs and their variation on the Great Barrier Reef. Mar Ecol Prog Ser 229:37-82

Berkelmans R (2009) Bleaching and mortality thresholds: How much is too much? In: van Oppen MJH, Lough JM (eds) Coral Bleaching. Ecological Studies. Springer, Berlin

Bright TJ, Kraemer GP, Minnery GA, Viada ST (1984) Hermatypes of the Flower Garden banks, northwestern Gulf of Mexico: a comparison to other Western Atlantic reefs. Bull Mar Sci 34:461-476

Bright TJ, McGrail DW, Rezak R, Boland GS, Trippett AR (1985) The Flower Gardens: a compendium of information. OCS Study MMS 85-0024, US Dep Inter Miner Manag Serv Gulf Mex OCS Reg New Orleans, Louisiana, 103

Clark R, Kracker LM, Taylor JC, Buckel CA (eds) (2014) Fish and benthic communities of the Flower Garden Banks National Marine Sanctuary: science to support sanctuary management. NOAA Tech Memo NOS NCCOS 179, Silver Spring, Maryland, 317

Clarke K, Gorley R, Sommerfield P, Warwick R (2014) Change in marine communities: an approach to statistical analysis and interpretation. PRIMER-E Ltd., Plymouth

Coles SL, Jokiel PL, Lewis CR (1976) Thermal tolerance in tropical versus subtropical Pacific reef corals. Pac Sci 30:159-166

CSA (Continental Shelf Associates) (1996) Long-term monitoring at the East and West Flower Garden Banks. US Dept of the Interior, Mineral Management Service, Gulf of Mexico OCS Study MMS 96-0046, New Orleans, Louisiana, 77

Dokken QR, MacDonald IR, Tunnell JW, Beaver CR, Boland GS, Hagman DK (1999) Long-term monitoring of the East and West Flower Garden Banks 1996-1997. US Dept of the Interior, Mineral Management Service, Gulf of Mexico OCS Study MMS 99-0005, New Orleans, Louisiana, 101

Dokken QR, MacDonald IR, Tunnell JW, Wade T, Beaver CR, Childs SA, Withers K, Bates TW (2001) Long-term monitoring of the East and West Flower Garden Banks, 1998-1999. US Dept of the Interior, Minerals Management Service, Gulf of Mexico OCS Study MMS 2001-101, New Orleans, Louisiana, 120
Dokken QR, MacDonald IR, Tunnell JW, Wade T, Withers K, Dilworth SJ, Bates TW, Beaver CR, Rigaud CM (2003) Longterm monitoring at the East and West Flower Garden Banks National Marine Sanctuary, 1998-2001: Final report. US Dept of the Interior, Minerals Management Service, Gulf of Mexico OCS Study MMS 2003-031, New Orleans, Louisiana, 90

Eakin CM, Morgan JA, Heron SF, Smith TB, Liu G, Alvarez-Filip L et al (2010) Caribbean corals in crisis: Record thermal stress, bleaching, and mortality in 2005. PLoS ONE 5:e13969

Gardner TA, Côté IM, Gill JA, Grant A, Watkinson AR (2003) Longterm region-wide declines in caribbean corals. Sci 301:958-960

Gittings SR, Boland GS, Deslarzes KJP, Hagman DK, Holland BS (1992) Long-term monitoring at the East and West Flower Garden Banks. US Dept of the Interior, Mineral Management Service, Gulf of Mexico OCS Study MMS 92-0006, New Orleans, Louisiana, 206

Hagman DK, Gittings SR (1992) Coral bleaching on high latitude reefs at the Flower Garden Banks, NW Gulf of Mexico. Proc 7th Int Coral Reef Sym 1:38-43

Helsel DR, Hirsch RM (2002) Statistical methods in water resources. In: Techniques of water-resources investigations of the United States Geological Survey. Book 4, Hydrologic analysis and interpretation, Washington DC, 522

Helsel DR, Mueller DK, Slack JR (2006) Computer program for the Kendall family of trend tests: U.S. Geological Survey Scientific Investigations Report 2005-5275, 4

Heron SF, Maynard JA, van Hooidonk R, Eakin CM (2016) Warming trends and bleaching stress of the world's coral reefs 1985-2012. Sci Reports 6:3842

Hughes TP, Kerry JT, Álvarez-Noriega M et al (2017) Global warming and recurrent mass bleaching of corals. Nature 543:373-377

Hughes TP, Anderson KD, Connolly SR, Heron SF, Kerry JT, Lough JM, Baird AH, Baum JK, Berumen ML, Bridge TC, Claar DC, Eakin CM, Gilmour JP, Graham NAJ, Harrison H, Hobbs JPA, Hoey AS, Hoogenboom M, Lowe RJ, McCulloch MT, Pandolfi JM, Pratchett M, Schoepf V, Torda G, Wilson SK (2018) Spatial and temporal patterns of mass bleaching of corals in the Anthropocene. Sci 359:80-83

IMaRS (Institute for Marine Remote Sensing) (2018) Daily seasurface temperature and chlorophyll data from Moderate Resolution Imaging Spectroradiometer (MODIS-Aqua) satellite sensor. University of South Florida's Institute for Marine Remote Sensing. St. Petersburg, FL. https://oceancolor.gsfc.nasa.gov

Jackson JBC, Donovan MK, Cramer KL, Lam V, Lam W (2014) Status and trends of caribbean coral reefs: 1970-2012. Glob Coral Reef Monit Network. IUCN, Gland, p 306

Jarosz E, Wijesekera HW, Teague WJ, Fribance DB, Moline MA (2014) Observations on stratified flow over a bank at low Froude numbers. J Geophys Res: Oceans 119:6403-6421

Johnston MA, Nuttall MF, Eckert RJ, Embesi JA, Slowey NC, Hickerson EL, Schmahl GP (2013) Long-term monitoring at the East and West Flower Garden Banks National Marine Sanctuary, 2009-2010, volume 1: technical report. US Dept of Interior, Bureau of Ocean Energy Management, Gulf of Mexico OCS Study BOEM 2013-215, New Orleans, Louisiana, 362

Johnston MA, Nuttall MF, Eckert RJ, Embesi JA, Slowey NC, Hickerson EL, Schmahl GP (2015) Long-term monitoring at the East and West Flower Garden Banks National Marine Sanctuary, 2011-2012, volume 1: technical report. US Dept of Interior, Bureau of Ocean Energy Management, Gulf of Mexico OCS Study BOEM 2015-027, New Orleans, Louisiana, 194

Johnston MA, Embesi JA, Eckert RJ, Nuttall MF, Hickerson EL, Schmahl GP (2016) Persistence of coral assemblages at East and West Flower Garden Banks, Gulf of Mexico. Coral Reefs $35: 821-826$ 
Johnston MA, Eckert RJ, Nuttall MF, Sterne TK, Embesi JA, Manzello DP, Hickerson EL, Schmahl GP (2017) Long-term monitoring at the East and West Flower Garden Banks National Marine Sanctuary, 2013-2015, volume 1: technical report. US Dept of Interior, Bureau of Ocean Energy Management, Gulf of Mexico OCS Study BOEM 2017-058, New Orleans, Louisiana, 186

Karnauskas M, Schirripa MJ, Craig JK, Cook GS, Kelble CR, Agar JJ, Black BA, Enfield DB, Lindo-Atichati D, Muhling BA, Purcell KM, Richards PM, Wang C (2015) Evidence of climatedriven ecosystem reorganization in the Gulf of Mexico. Glob Chang Biol 21:2554-2568

Kohler KE, Gill SM (2006) Coral Point Count with Excel extensions (CPCe): A Visual Basic program for the determination of coral and substrate coverage using random point count methodology. Comput Geosci 32:1259-1269

Lang JC, Marks KW, Kramer PA, Kramer PR, Ginsburg RN (2012) AGRRA (Atlantic and Gulf Rapid Reef Assessment) protocols, v5.4. Available from: http://www.agrra.org

Manzello DP, Berkelmans R, Hendee JC (2007) Coral bleaching indices and thresholds for the Florida Reef Tract, Bahamas, and St. Croix. US Virgin Islands. Mar Poll Bull 54:1923-1931

Monroe AA, Ziegler M, Roik A, Röthig T, Hardenstine RS, Emms MA, Jensen T, Voolstra CR, Berumen ML (2018) In situ observations of coral bleaching in the central Saudi Arabian Red Sea during the 2015/2016 global coral bleaching event. PLoS ONE 13(4):e0195814

Muller-Karger FE, Smith JP, Werner S, Chen R, Roffer M, Liu Y, Muhling B, Lindo-Atichati Lamkin J, Cerdeira-Estrada S, Enfield DB (2015) Natural variablity of surface oceanographic conditions in the offshore Gulf of Mexico. Prog in Oceanogr 134:54-76

Mumby PJ, Steneck RS (2011) The resilience of coral reefs and its implications for reef management. In: Dubinsky Z, Stambler N (eds) Coral Reefs: An Ecosystem in Transition. Springer, Dordrecht, pp 509-519

NOAA Coral Reef Watch (2017) NOAA Coral Reef Watch Daily Global 5-km Satellite Virtual Station Time Series Data for Flower Garden Banks, Texas, Jan. 1, 2016-Dec. 30, 2017. College Park, Maryland. NOAA Coral Reef Watch. Data set accessed 2017-06-21 at https://coralreefwatch.noaa.gov/vs/data/ flower_garden.txt
Ogden JC, Wicklund RL (1988) Mass bleaching of coral reefs in the Caribbean: A research strategy. National Undersea Research Program Research Report 88-2 US Dept of Commerce, NOAA, Rockville, Maryland, 51

Precht WF, Aronson RB, Deslarzes KJP, Robbart ML, Gelber A, Evans D, Gearheart B, Zimmer B (2006) Long-term monitoring at the East and West Flower Garden Banks, 2002-2003: Final report. US Dept of the Interior, Mineral Management Service, Gulf of Mexico OCS Study MMS 2004-031, New Orleans, Louisiana, 182

Precht WF, Aronson RB, Deslarzes KJP, Robbart ML, Zimmer B, Duncan L (2008) Post hurricane assessment at the East Flower Garden Bank long-term monitoring site: November US Dept of the Interior, Mineral Management Service, Gulf of Mexico OCS Study MMS 2008-019, New Orleans, Louisiana, 39

R Core Team (2012). R: A language and environment for statistical computing. R Foundation for Statistical Computing, Vienna, Austria. ISBN 3-900051-07-0. http://www.R-project.org

Schmahl GP, Hickerson EL, Precht WF (2008) Biology and ecology of coral reefs and coral communities in the Flower Garden Banks region, northwestern Gulf of Mexico. In: Riegl B, Dodge R (eds) Coral Reefs of the USA. Springer, Netherlands, pp 221-261

TABS (Texas Automated Buoy System Database) (2018) Hourly temperature and salinity data from TABS buoys $\mathrm{V}$ and $\mathrm{N}$. Geochemical and Environmental Research Group, Texas A\&M University, College Station, TX. http://tabs.gerg.tamu.edu/Tglo

van Hooidonk R, Maynard JA, Tamelander J, Gove J, Ahmadia G, Raymundo L, Williams G, Heron S, Planes S (2016) Local-scale projections of coral reef futures and implications of the Paris Agreement. Nature Sci Reports 6:39666

Zimmer B, Duncan L, Aronson RB, Deslarzes KJP, Deis D, Robbart ML, Precht WF, Kaufman L, Shank B, Weil E, Field J, Evans DJ, Whaylen L (2010) Long-term monitoring at the East and West Flower Garden Banks, 2004-2008. Volume I: Technical report. US Dept of the Interior, Bureau of Ocean Energy Management, Regulation, and Enforcement, Gulf of Mexico OCS Study BOEMRE 2010-052, New Orleans, Louisiana, 310

Publisher's Note Springer Nature remains neutral with regard to jurisdictional claims in published maps and institutional affiliations. 